\title{
Focus in an active/agentive alignment system - the case of Beria (Saharan)
}

\author{
Angelika Jakobi
}

Bayreuth

Beria, a member of the Saharan language family, is one of the rare languages in Africa exhibiting both an ergative and an active/agentive alignment system of grammatical relations. ${ }^{1}$ While the active/agentive pattern is shown by the participant reference markers, the ergative pattern is attested both in the constituent order and in the focus markers on the core constituents. In the pragmatically unmarked constituent order, the Agent constituent precedes the Patient constituent. An unmarked single constituent immediately preceding the verb may represent a Patient or a Subject argument. In this position, the Agent constituent requires the clitic GU. The focused Patient and Subject constituents are both either marked by the clitic DI or by a cleft construction.

\section{Introduction}

Beria, also known by the xenonym Zaghawa, is spoken by some 150.000 people in the Wadai and Darfur region on the border of Chad and Sudan. Along with the now extinct Berti language, Beria forms the eastern branch of the Saharan language family, the western branch being represented by Kanuri-Kanembu and Teda-Daza.

1 I am very grateful to the anonymus reviewer for having pointed out to me several weaknesses in the previous version of this paper. I wish to thank Walter Bisang, Orin Gensler, and Christa König, for suggesting to me that Beria has an active/agentive alignment system. I would also like to thank both Gudrun Miehe for discussing with me the system of participant reference marking and Theda Schumann for reading the final version of the paper. They are, of course, not responsible for any remaining errors or shortcomings. This paper is based on language data collected in the course of several field research periods in Chad between 1998 and 2002. The research was carried out within the framework of the project SFB 295/C4 at the University of Mainz. I wish to express my gratitude to the Deutsche Forschungsgemeinschaft for sponsoring this project. 
Generally, there are three basic grammatical relations between arguments and predicates, the Agent (A) and the Patient (P) of a transitive sentence, and the single argument or Subject (S) of an intransitive sentence. In a nominativeaccusative alignment system, $\mathrm{S}$ patterns with $\mathrm{A}$, and $\mathrm{P}$ differently, in an absolutive-ergative alignment system $\mathrm{S}$ patterns with $\mathrm{P}$, and A differently. An active/agentive alignment system has both features of an accusative system ( $\mathrm{S}=$ $A$, see Diagram 1) and of an ergative system ( $\mathrm{S}=\mathrm{P}$, see Diagram 2). More precisely, in an active/agentive alignment system the single argument of intransitive sentences splits structurally and patterns either with the Agent $\left(\mathrm{S}_{\mathrm{A}}=\right.$ A) or with the Patient $\left(S_{P}=P\right)$ of transitive sentences. (see Diagram 3).

Diagram 1: (Nominative-) Accusative system (S = A, P)

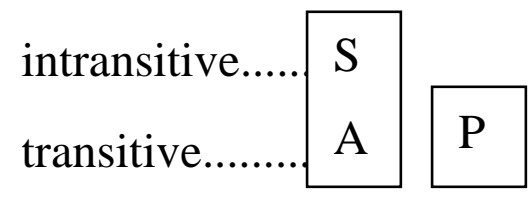

Diagram 2: (Absolutive-) Ergative system ( $\mathrm{S}=\mathrm{P}, \mathrm{A})$

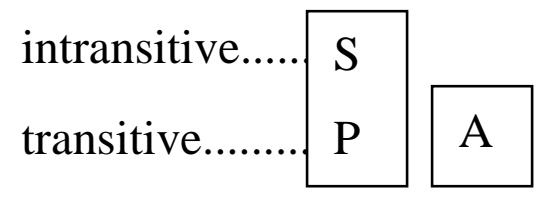

Diagram 3: Active/agentive system $\left(\mathrm{S}_{\mathrm{A}}=\mathrm{A}, \mathrm{S}_{\mathrm{P}}=\mathrm{P}\right)$

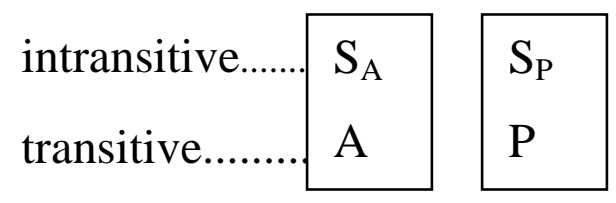

Languages rarely exhibit solely one system of grammatical relations. German, for example, has an accusative system in which the Subject of an intransitive verb is encoded like the A argument of a transitive verb, e.g. "ich habe geschlafen", "ich habe ihn gefangen". But with a small class of verba sentiendi, the single participant of an intransitive sentence is encoded like a P argument of a transitive sentence: "mich friert (es)", "mich freut (es)", "mich/mir dünkt”, "mir scheint", "mir träumte". The pronoun "es" here functions as a dummy subject representing an impersonal Agent.

Two systems of grammatical relations are also attested in Loma, a Mande language of Liberia. Loma exhibits an ergative pattern in its noun case system: The Subject of an intransitive verb and the Patient of a transitive verb determine 
verb-initial consonant lenition. The Loma pronoun system, however, exhibits an active/agentive system. Loma has two sets of person pronouns, one set marking the subject, the other the object. When the Subject of an intransitive verb is stative, it is encoded with an object pronoun, when the Subject is active, it is encoded with a subject pronoun (Rude 1982).

Languages like Loma and Beria with an active/agentive and ergative alignment system appear to be rare in Africa. Outside of Africa these systems are attested in Amerindian languages of northern and southern America, in Caucasian languages, and in various languages of Asia and Australia (Klimov 1974, Dixon 1994).

Grammatical relations are generally distinguished by constituent order, agreement marking on the verb, and/or case marking. In the following, I will first deal with agreement marking and then with constituent order and focus marking in Beria.

\section{Participant reference marking on the verb}

Beria is a polysynthetic language, that is a finite verb can express a whole sentence. The participant reference markers on the verb represent the arguments of the sentence. As shown in Table 1, there are two series of participant reference markers, a series of prefixed object markers, and a series of suffixed subject markers. ${ }^{2}$

2 In both series, identical forms are distinguished by an additional tonal morpheme in the plural. Each object prefix has two allomorphs depending on the following segment. Before a vowel, the vowelless allomorph of the prefix is selected, before a consonant the prefix is extended by an epenthetic vowel whose quality depends on the following vowel (Jakobi \& Crass 2004: 41). Beria has two rhotics: [r] represents an alveo-lateral flap to be distinguished from the apico-alveolar flap [r]. The distribution of the third person subject suffixes $-r,-n$ and $\varnothing$ is lexicalized. The suffix $-r$ is deleted under two different conditions, i) after a consonant-final verb root, and ii) in the perfective aspect of some verbs where the deletion of -r appears to be lexicalized (Jakobi \& Crass 2004: 59). 
Table 1: Participant reference markers on the verb

\begin{tabular}{|c|c|c|c|}
\hline & & $\begin{array}{c}\text { Object markers for P and the } \\
\text { principal argument of a } \\
\text { medium verb }\end{array}$ & Subject markers for A and S \\
\hline \multirow{3}{*}{ Sg } & 1 & $(\mathrm{~V})-$ & $-\mathrm{g}$ \\
\cline { 2 - 4 } & 2 & $\mathrm{n}(\mathrm{V})-$ & $-\mathrm{n}$ \\
\cline { 2 - 4 } & 3 & $\varnothing$ & $-\mathrm{r},-\mathrm{n}, \varnothing$ \\
\hline \multirow{3}{*}{ Pl } & 1 & $\mathrm{t}(\mathrm{V})-$ & $-\mathrm{d}$ \\
\cline { 2 - 4 } & 2 & $\mathrm{n}(\mathrm{V})-$ & $-\mathrm{b}$ \\
\cline { 2 - 4 } & 3 & $\varnothing$ & $-\mathrm{r},-\mathrm{n}, \varnothing$ \\
\hline
\end{tabular}

Beria distinguishes between active and medium verbs. Active verbs may be further subdivided into transitive active and intransitive active verbs. Transitive active verbs have two participant reference markers: one object marker, cf. nó- and $\varepsilon$ - in examples (1) and (2), and one subject marker, cf. -g in (1) and -r in (2). The object markers represent the $\mathrm{P}$ argument, the subject markers the $\mathrm{A}$ argument. $^{3}$

$\begin{array}{llll}\text { (1) nó- } & \text { ró } & -g & \text {-I } \\ \text { OJ:2Sg } & \text { marry } & \text { SJ:1Sg } & \text { IPV } \\ \text { P } & & \text { A } & \end{array}$

'I will marry you.'

$\begin{array}{llll}\text { (2) } \quad \mathcal{\varepsilon}- & \text { ś } & -r & -1\end{array}$

$\begin{array}{llll}\mathrm{OJ}: 1 \mathrm{Sg} & \text { eat } & \mathrm{SJ}: 3 & \mathrm{IPV}: \mathrm{Pl} \\ \mathrm{P} & & \mathrm{A}\end{array}$

'They [the lions] will eat me.'

Intransitive active verbs have one participant referent marker which is selected from the series of subject markers, cf. -g in (3) and $-r$ in (4). The comparison of $-g$ representing the A argument in (1) with the $S$ argument in (3), and of $-r$

3 Abbreviations used in this paper: $1,2,3$ = first, second, third person, $\mathrm{A}=$ agent, $\mathrm{A}_{\text {impers }}=$ impersonal Agent, ABS = absolutive, ADV = adverbializer, APPL = applicative, AUX = auxiliary, BEN = beneficient, CAUS = causative, $\mathrm{COP}=$ copula, FOC $=$ focus, IPV = imperfective, $\mathrm{MED}=$ marker of medium verbs, $\mathrm{O}=$ object, $\mathrm{OJ}=$ object marker, $\mathrm{P}=$ patient, $\mathrm{PFV}=$ perfective, $\mathrm{Pl}=$ plural, $\mathrm{POSS}=$ Possessive, $\mathrm{PP}=$ person pronoun, Pred $=$ verbless predicate, $\mathrm{S}=$ single argument of intransitive sentence, $\mathrm{Sg}=$ singular, $\mathrm{S}_{\mathrm{A}}=$ Agent-like subject, $\mathrm{SJ}=$ subject marker, $\mathrm{S}_{\mathrm{P}}=$ Patient-like subject, $\mathrm{V}=$ verb. 
representing the A argument in (2) with the S argument in (4) reveals that $S$ patterns with A. This pattern is characteristic of an accusative alignment system.

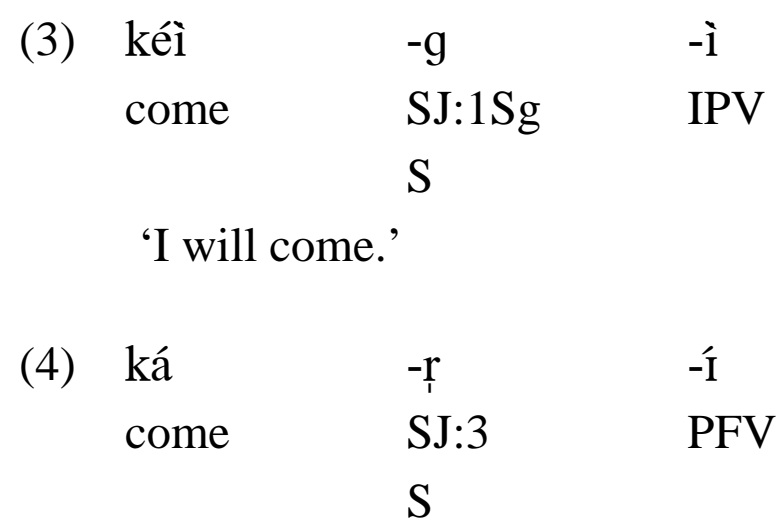

'He will come.'

Medium verbs are subdivided in two groups. One group is characterized by an s- prefix glossed MED in (5) and (6). This prefix occurs in the imperfective only. Verbs of the other group do not take this prefix, cf. (8).

Although most medium verbs have one participant only, they take two participant reference markers. That is, although they are semantically intransitive, they have a structure comparable to a transitive active verb, compare (8) to (2).

Medium verbs are, however, clearly distinct from transitive active verbs because they invariably take the third person subject marker, $-r,-n, \varnothing$. This is illustrated in (5), (6), (7), (8), and (11). As for the object marker, any morpheme may be selected, cf. $\varepsilon$ - in (5), nó- in (6), $\varnothing$ in (7), t $\varepsilon^{-}$- in (8). This suggests that it is the object marker that represents the principal argument of a medium verb. ${ }^{4}$ The third person subject marker, however, is a dummy subject representing an impersonal Agent. Such a construction, therefore, resembles the German construction 'es freut mich', 'mich friert's'.

As the principal argument of a semantically intransitive medium verb is encoded like the Patient of a transitive sentence, this patterning exhibits an ergative alignment system, compare (5) to (2), (6) to (1).

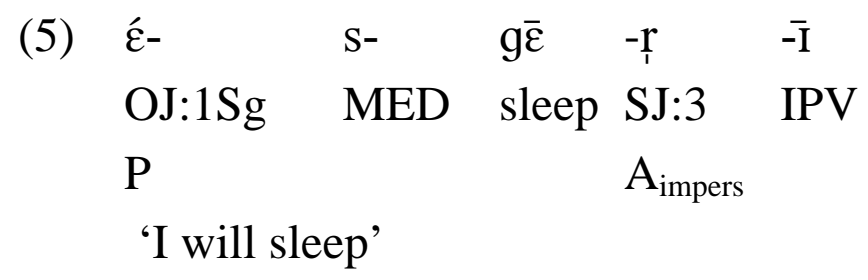

4 I owe the term 'principal argument' to Mark S. Ortman's paper "Teda verb classes and their morphology in light of verbal paradigms" (ms 2003). 
(6) nó- s- kù $\quad$-r $\quad$-ì

OJ:2Sg MED get.lost SJ:3 IPV

$\mathrm{P} \quad \mathrm{A}_{\text {impers }}$

'You will get lost.'

(7) Ø áú -n -í

$\mathrm{OJ}: 3$ stop $\mathrm{SJ}: 3 \quad \mathrm{PFV}$

$\mathrm{P} \quad \mathrm{A}_{\text {impers }}$

'He stopped.'

(8) té- kédè $\quad-r \frac{1}{1} \quad$-ì

OJ:1Pl fall SJ:3 IPV

P A impers

'We will fall.'

In the perfective, some active transitive and intransitive verbs and some medium verbs delete the third person subject marker, cf. (9) to (11). The deletion of this morpheme is not predictable but lexicalized.

(9) $\varnothing \quad$ kì- nà $\varnothing \quad$-í

OJ:3 PFV:3 buy SJ:3 PFV

$\mathrm{P} \quad \mathrm{A}$

'He has bought [it].'

(10) ká- gà $\varnothing \quad$-í

APPL come SJ:3 PFV:Pl

$\mathrm{S}$

'They came.'

(11) né- gé

OJ:2Sg sleep SJ:3 PFV

$\mathrm{P} \quad \mathrm{A}_{\text {impers }}$

'You slept.'

As the zero encoding of $A$ in (9) and of $A_{\text {impers }}$ in (11) is identical to the zero encoding of $S$ in (10), the patterning of $S$ with $A$ or $A_{\text {impers }}$ again shows the characteristics of an accusative alignment system. 
Thus, Beria has two kinds of intransitive verbs with a single participant: i) Intransitive active verbs encode the single participant with a subject morpheme. ii) Semantically intransitive medium verbs encode the single participant with an object morpheme. The different encoding of the single partipant either like an A or like a $\mathrm{P}$ argument exhibits the characteristic pattern of an active/agentive alignment system.

The next section, however, shows that the system of grammatical relations reflected in the constituent order and in the focus markers rather follows the ergative pattern $\mathrm{S}=\mathrm{P}$.

\section{The ergative system in constituent order and focus marking}

Beria is a verb-final language. The pragmatically unmarked constituent order is SOV in transitive sentences, cf. (12). That is, in a two argument sentence A precedes $\mathrm{P}$, and $\mathrm{P}$ precedes the verb. In intransitive sentences, the basic constituent order is SV. That is, the single argument S precedes the verb, cf. (13).

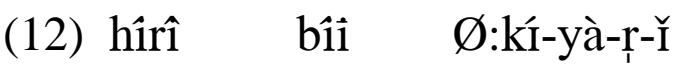

cow:Pl water OJ:3:PFV:3-drink-SJ:3-PFV:Pl

A $P$ P A

'The cows have drunk water.'

(13) hîrî ká-gà-Ø-Í

cow:Pl APPL-come-SJ:3-PFV:Pl

$\mathrm{S}$

$\mathrm{S}$

'The cows have come.'

Depending on the semantics of the verb, a single unmarked core constituent immediately preceding a verb can either be conceived of as $\mathrm{P}$, as illustrated in (14) and (15), or as S, as in (13), (16) and (17).

(14) bîî Ø:wár-g-ì

water OJ:3:pour.on.the.ground-SJ:1Sg-IPV

$\mathrm{P} \quad \mathrm{P} \quad \mathrm{A}$

'I will pour water on the ground.' 
(15) bágú-ógó

Ø:kú-gú-rîî

wife-POSS:3Sg

$\mathrm{P}$

OJ:3:PFV:3-call-SJ:3-PFV

P

A

'He called his wife.'

(16) ว๊̀ ká-rí-Í

person come-SJ:3-PFV

$\mathrm{S} \quad \mathrm{S}$

'The person has come.'

(17) áī kí غ̀-g-ì

PP:1Sg leave AUX-SJ:1-PFV

$\mathrm{S}$

$\mathrm{S}$

'I will leave.'

The examples (13) to (17) illustrate that the unmarked S or P constituents take the position immediately before the verb. If the A constituent shifts to this position, it requires the clitic GU, ${ }^{5}$ as shown in (18) and (19). The P constituent, however, does not require a marker even if it precedes A, cf. (19). The fact that the A constituent takes a marker and that both the $\mathrm{S}$ and $\mathrm{P}$ constituents are unmarked reveals the characteristic ergative pattern.

In (18) and (19) the clitic GU marks an animate and volitional Agent and in (20) and (21) an inanimate force. This suggests that GU marks the Actor rather than just the Agent. The term Actor is conceived of as a semantic macrorole comprising several semantic roles and thematic relations (Van Valin 2001: 31).

$$
\begin{array}{ll}
\text { bágú-ógó=gú } & \text { Ø:kú-gú-r-1̂-1 } \\
\text { wife-POSS:3Sg=FOC } & \text { OJ:3:PFV:3-call-SJ:3-PFV }
\end{array}
$$

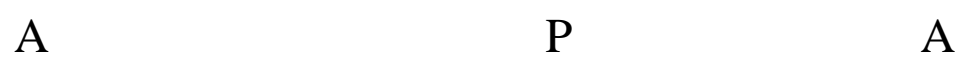

'It's his wife who called him.'

(19) jàá:Ø

$$
\text { bòrū }=g \bar{u} \quad \text { sà̀ } \quad \text { Ø:gí-n-Ø-í }
$$

child:ABS man=FOC ERG $_{\text {hit }}$

$\mathrm{P}$

A

OJ:3:PFV:3-AUX-SJ:3-PFV

'It's the man who hit the child.'

5 Depending on the [ATR] feature of the preceding vowel, the clitic GU is realized as $[\mathrm{gu}]$ or $[\mathrm{gu}]$ and the clitic DI as $[\mathrm{dI}]$ or $[\mathrm{di}]$. 
(20) òrfū $=g \bar{u} \quad$ kíjí $\quad$ :sè-ì-ri-Í

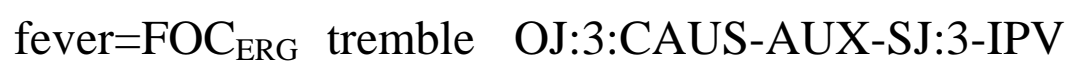
A $\mathrm{P}$
A

'The fever made him tremble.'

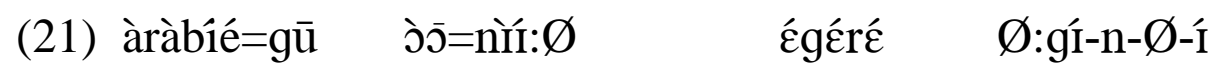

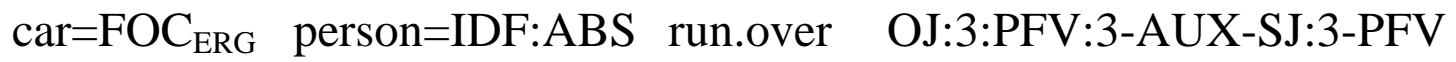
A $\quad \mathrm{P} \quad \mathrm{P} \quad \mathrm{A}$

'The car has run over a certain person.'

The characteristic patterning of $\mathrm{P}$ with S, and A differently, is also attested in the focus markers employed for these constituents. As illustrated in the sentences below, the clitic DI marks both the focused P constituent, cf. (22), and the S constituent, cf. (23) to (25).

(22) náá=dî nè-gèr-g-Ì

$\mathrm{PP}: 2 \mathrm{Sg}=\mathrm{FOC}_{\mathrm{ABS}} \quad$ OJ:2-look.for-SJ:1Sg-IPV

$\begin{array}{lll}P & P\end{array}$

'It's you I am looking for.'

(23)

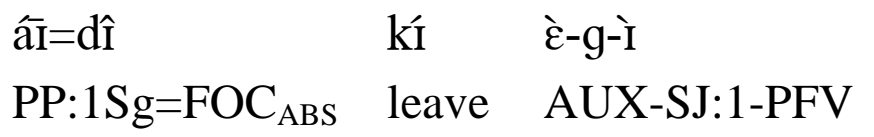

$\mathrm{S}$

$\mathrm{S}$

'It's me who will leave.'

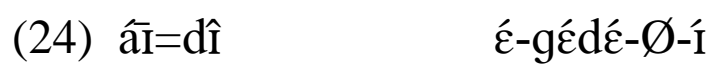

$\mathrm{PP}: 1 \mathrm{Sg}=\mathrm{FOC}_{\mathrm{ABS}} \quad$ OJ:1Sg-fall-SJ:3-PFV

$\mathrm{P} \quad \mathrm{P} \quad \mathrm{A}_{\text {impers }}$

'It's me who has fallen.'
(25) sùltăn=dì
Ø:nÍ-Ø-і́
sultan $=\mathrm{FOC}_{\mathrm{ABS}}$
OJ:3:die-SJ:3-PFV
$\mathrm{P}$
$\mathrm{P} \quad \mathrm{A}_{\text {impers }}$

'It's the sultan who has died.'

Example (26) illustrates that both a focused $\mathrm{P}$ and a focused A constituent may occur in one sentence. 

(26) bì̀ kî=dî ábā égî=gú $\quad$ Ø:sî-é-rị-1̂̀ house this $=\mathrm{FOC}_{\mathrm{ABS}}$ father my=FOC $\mathrm{ERG}_{\mathrm{A}}$ OJ:3:build-PFV:3-SJ:3-PFV $\begin{array}{llll}\mathrm{P} & \mathrm{A} & \mathrm{P} & \mathrm{A}\end{array}$
'It's this house that my father has built.'

So far, the description has shown that the distribution of GU and DI exhibits an ergative pattern. GU is solely employed as contrastive focus marker required when the A constituent immediately precedes the verb, a position which is not admitted for the unmarked A constituent. This rule is not applied, however, if the A constituent is preceded by a clefted P constituent, cf. (29) and (30) below. $\mathrm{DI}$, in contrast, is used as contrastive focus marker of the P and S constituent.

Apart from its focus marking function, DI is also employed as non-verbal predication marker, cf. (27) and (28). It is assumed that the focus marker DI and the nonverbal predication marker DI have a common origin.

(27) áīi $=$ î

PP:1Sg=Pred

'It's me.'

(28) kèkkì=dî

here $=$ Pred

'It's here.'

The cleft construction is another device to focus both the $\mathrm{P}$ and the $\mathrm{S}$ constituent. The clefted constituent is marked by the clitic copula I. ${ }^{6}$ This is the third person form of the copula of identification. The rest of the sentence remains unchanged.

If $P$ is clefted, the A constituent does not require the clitic GU, even if it immediately precedes the verb as in (29). The cleft construction is restricted to focused single nouns, cf. (29), and question words, cf. (31) and (32). Focused person pronouns and focused complex noun phrases, however, require the marker DI. In other words, the employment of the cleft construction marking the focused P and S constituent is more restricted than the employment of DI.

$6 \quad$ I is realized as [I] or [i] depending on the [ATR] feature of the preceding vowel. In the singular I takes a mid tone, in the plural a high tone. 
(29)
ábā égî:Ø
Ø:kì-nà-Ø-Í
car=COP:Sg:ABS
father my:ERG
OJ:3:PFV:3-buy-SJ:3-PFV
$\mathrm{P}$
A
$\mathrm{P}$
A

'It's the car that my father has bought.'

(30)
gùứ $=\overline{\mathrm{I}}$
Íà:Ø
fàá-r
Ø:kekk-í
paste $=$ COP:Sg:ABS
OJ:3:give:SJ:3-PFV

$\mathrm{P}$

A

BEN

'It's paste that the mother has given to the child.'

(31)
nứrá $=\overline{\mathrm{I}}$

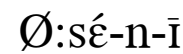
what=COP:Sg:ABS
OJ:3:eat-SJ:2-PFV
$\mathrm{P}$
$\mathrm{P}$
A
'What is it that you have eaten?'

(32)
nánà='́
ká-gà-Ø-Í
who:Pl=COP:Pl:ABS
APPL-come-SJ:3-PFV:Pl

S

$\mathrm{S}$

'Who is it who has come?'

As the cleft construction is restricted to focusing $\mathrm{S}$ and $\mathrm{P}$, and as the $\mathrm{A}$ constituent is focused differently, this patterning again shows the characteristic features of an ergative system of grammatical relations.

A few medium verbs like 'learn' and 'enter/dress' have two $\mathrm{P}$ constituents. This double P construction is shown in example (33) to (35) where the employment of DI and the cleft construction attest that the focused constituents represent a $\mathrm{P}$ argument.

(33) jant
fàmâl=dî
àrmá:Ø
Ø:áwáá-rị̂î
Jamal $=\mathrm{FOC}_{\mathrm{ABS}}$
Arabic:ABS
OJ:3:learn-SJ:3-PFV
$\mathrm{P}$
$\mathrm{P}$
$\mathrm{P}$
$\mathrm{A}_{\text {impers }}$

'It's Jamal who has learnt Arabic.'

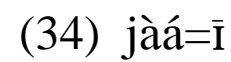

child=COP:Sg:ABS

$\mathrm{P}$
àráp:Ø

Arabic:ABS

$\mathrm{P}$
Ø:áwáá-rị-Ǐ

OJ:3:learn-SJ:3-PFV:Pl

$\mathrm{P}$

$A_{\text {impers }}$

'It's the children who have learnt Arabic.' 
(35) àráp $=\overline{\mathrm{I}}$ jáà:Ø $\quad$ Ø:áwáá-ri-ı̌

Arabic=COP:Sg:ABS child:Pl:ABS OJ:3:learn-SJ:3-PFV:Pl

$\mathrm{P}$ $\mathrm{P}$

$\mathrm{P} \quad \mathrm{A}_{\text {impers }}$

'It's Arabic that the children have learnt.'

\section{Semantic motivation}

The assignment of grammatical relations always has a semantic motivation. In Beria, the position of the participant reference markers which precede or follow the verb stem, allows to make a fine distinction between the different semantic roles played by the participants. The object markers preceding the verb stem either represent the $\mathrm{P}$ argument of a transitive active verb or a patientive principal argument of a semantically intransitive medium verb. The subject marker following the verb stem either represent the A argument of a transitive active verb or an agentive single argument of an intransitive active verb. An agentive single participant - one who comes and leaves - acts volitionally and is therefore encoded like an A argument. A patientive single participant - one who sleeps, dies, or falls - does not control the event but is rather affected by it. The participant in such an event plays, therefore, rather the role of an undergoer. Medium verbs, in particular, typically denote events which affect the body or mind of the participant (Kemmer 1993). In Beria, this P-like role of the principal argument is, therefore, encoded with an object prefix.

In a verb final language, the focus markers on the core constituents do not allow to make a fine distinction between agentive and patientive single participants in an intransitive sentence. The most important task of a focus marker in a verb final language is to show whether a core constituent preceding the verb plays an agentive or patientive role. The focused single participant of intransive sentences, in contrast, could theoretically either be encoded like an A or P argument. In Beria, as illustrated in (23), (24), (25), (32) the single participant is always focused like the $\mathrm{P}$ argument of a transitive sentence.

Interestingly, as shown in (33) to (35), a few medium verbs have two $\mathrm{P}$ arguments. According to Mithun (1991: 517), "it is not uncommon in agentpatient systems, where the morphology permits it, for both core arguments of a transitive clause to be classified grammatically as patients if neither participant performs/effects/instigates or controls.” 


\section{Summary}

The paper shows that Beria exhibits two systems of grammatical relations, an active/agentive and an ergative alignment system. The ergative pattern is exhibited 1) in the constituent order, 2) in the focus markers GU and DI, and 3) in the cleft construction which is restricted to the $\mathrm{P}$ argument, the single argument of an intransitive active verb or to the principal argument of a semantically intransitive medium verb. The participant reference markers, in contrast, show the active/agentive pattern. Accordingly, the agentive single participant of an intransitive sentence is encoded like an A argument. The patientive participant of a semantically intransitive sentence, in contrast, is encoded like a P argument.

According to typological studies, languages having an active/agentive system of grammatical relations, as shown in Diagram 3, tend to share a number of morphological and syntactic characteristics. Beria confirms several of these:

i) Beria is a polysynthetic language ("The morphological structure of the verb is often characterized in such languages by polysyntheticism", Klimov 1975: 17).

ii) The active/agentive system occurs in the participant reference markers on the verb ("Active/agentive patterns appear especially frequent in pronominal affixes within verbs”, Mithun 1991: 542 ).

iii) The semantic motivation for the different morphosyntactic encoding of the arguments is the sensitivitiy to active/agentive versus inactive/patientive participants.

iv) There is "no opposition of transitive and intransitive verbs" (Klimov 1975: 18). In Beria, medium verbs with one participant are morphologically transitive verbs with two participant reference markers.

Moreover, in the perfective form of many verbs, the third person subject marker is deleted. This marker encodes both the third person A argument of a transitive sentence and, perhaps less important, the impersonal A argument of a semantically intransitive sentence. The deletion of the third person subject marker indicates that in the event described by the verb, the Agent - which is otherwise conceived of as an important role in a transitive sentence - is of little importance. 


\section{Angelika Jakobi}

\section{$6 \quad$ References}

Dixon R. M.W. 1994. Ergativity. Cambridge: Cambridge U.P.

Jakobi A. \& J. Crass. 2004. Grammaire du beria (langue saharienne). Köln: Köppe.

Kemmer S. 1993. The Middle Voice. Amsterdam and Philadelphia: Benjamins.

Klimov G.A. 1974. On the character of languages of active typology. Linguistics 131: 11-25.

Mithun M. 1991. Active/agentive case marking and its motivations. In: Language 67: 510546.

Rude N. 1982. Ergativity in Loma. In: Studies in African Linguistics 14,3: 265-281.

Van Valin R.D. 2001. An Introduction to Syntax. Cambridge: Cambridge U.P. 